\title{
Problem-Solving Training in Character Multidiscipline in PET-Health/Natal-RN for Undergraduate Students
}

\author{
Iramara Lima Ribeiro, Antônio Medeiros Júnior \\ Federal University of Rio Grande do Norte (UFRN), Natal, Brazil \\ Email: iramararibeiro@hotmail.com, amjunior@ufrnet.br
}

Received 11 May 2015; accepted 28 December 2015; published 31 December 2015

Copyright ( 2015 by authors and Scientific Research Publishing Inc.

This work is licensed under the Creative Commons Attribution International License (CC BY). http://creativecommons.org/licenses/by/4.0/

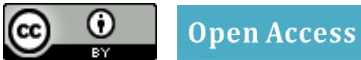

\begin{abstract}
The undergraduate training points to teaching methodologies where students act on their learning processes. Underlying this perspective, the under graduation in health of Federal University of Rio Grande do Norte offers the discipline of Saúde e Cidadania (SACI-Health and Citizenship), held in different health centers at Natal, state of Rio Grande do Norte, Brazil. The aim of this study is to analyze between 2009 and 2011, the strengths and weaknesses of this experience, according to former students. 25 learning portfolios written by students were analyzed with the aid of Alceste 4.9 software. The results show the value of teamwork to facing the problems and the existence of formative stimuli toward the comprehensive care. Emerging as weaknesses, the difficulties in living together in the labor process are that students miss the low supply of multidisciplinary courses throughout the training. It is concluded that the SACI-Health and Citizenship gives students a different look to the psychic, social, economic and cultural factors that underlie problems and health practices.
\end{abstract}

\section{Keywords}

Education, Higher Education, Interdisciplinary Communication, Health

\section{Introduction}

Brazil has been seeking improvements in higher education in health, motivated from the adoption of the National Curriculum Guidelines in the first decade of the 2000s. Before teaching that it was traditionally more oriented to Flexnerian model, focused on specialization with many disconnected disciplines at the undergraduate, generating a system of fragmented attention and facing to the disease [1]. Right now it has been taking new teaching 
methodologies, among which stand out the active methodologies. In this way, students stop being spectators and start to play the leading role in their learning process. Nevertheless, considering that changes bring innovations and so generate mistrust in academy, the new methodologies emerge still timid in Higher Education Institutions.

Among the active methods, the Federal Universidade Federal do Rio Grande do Norte (UFRN) adopts the problematization methodology in health undergraduate, by the multidisciplinary discipline SACI (Saúde e Cidadania/Health and Citizenship). SACI is linked to the educational component of PET-Health Family (Programa de Educação pelo Trabalho para a Saúde da Família/Education Program by Work for Health Family). This discipline inserts into Health Centers (HC), students in the early periods of Nursing, Medicine, Dentistry, Pharmacy, Physiotherapy, Nutrition, Speech Therapy, Management of Systems and Health Services, BioMedicine and Social Service, collectively that interact in tutorial groups, guided by professors (tutors) and service professionals (preceptors).

This article aims to analyze strengths and weaknesses of SACI in vocational training of students between 2009 and 2011 from formative experiences of them during the course.

\section{Methodology}

This is a documentary study which, according to Gil [2], takes place from materials that have not yet received an analytical treatment, or can even be reworked in accordance with the objects of the research and presents the advantage of using a rich and stable data source. Besides, is low cost and does not require direct contact with the subjects. It is emphasized that this research is part of a dissertation, which is still being completed.

The study material was learning portfolios written by the students of SACI between 2009 and 2011, at Natal-RN. Portfolios constitute a strategy of learning assessment that are documents written by students from their reflections on learning throughout the teaching process.

Observing the ethical implications of research and in accordance with Resolution 466/2012 of the National Health Council [3], this project was approved by the Ethics Committee in Research of the University Hospital Onofre Lopes (CEP/HUOL) under protocol 638/11, CAAE: 0065.0.294.000-11.

After collecting data it was carried out brief reading of portfolios, by choosing 25 of them to perform the analysis. The selection criteria included: emphasis on contributions of SACI for professional health training; presence of critical-reflexive content articulated with formative experiences in actual teaching scenarios; identification of the main weaknesses of the disciplines; good writing and good communication.

The analysis of portfolios of learning was developed with the help of software Alceste ${ }^{\odot}$ (Par Analyse Lexicale Contexte d'Segments of an Ensemble of Texte-Lexical Contextual Analysis of a Set of Segments of Text), version 4.9. The program performs lexical analysis using a Descending Hierarchical Classification (CHD). Thus, each text written during the study period corresponding to an initial context Unit (ICU), and the set of them is the corpus analysed.

The UCI were separated by command lines in which each student received an identification number, preserving its identity, including variables such as gender, course and HC where attended during the course.

According to Camargo [4], the formed corpus is processed by Alceste which divides the material in Elementary Context Units (UCE), classified according to their respective vocabularies. There is another division by the frequency of words based on their roots. Thus, the CHD is performed with the chi-square test and the software provides the dendrogram that expresses the UCE more characteristics of each class (statistically significant).

Regarding the words, we only consider those with a frequency of greater than or equal to the average frequency of the class and with the largest chi square occurrence. The presence of positive sign (+) after the word indicates that it is in its reduced form. Preserving the autonomy of the individuals involved, their names were replaced by the following symbols: for woman and for man.

\section{Results and Discussion}

In the phase of data collection, we obtained 386 leaning portfolios of SACI and through fluctuating reading. We selected 105 to identify those that contained the description of the content covered and the experiences that were obtained during the discipline. After the portfolios were reread, remaining a total of 55 in this phase, followed by a deeper reading, according to the same criteria (content and experiences), especially in relation to the experiences, remaining 25 students' portfolios of seven USF that were called here of (4), B (2) C (7), D (3) and (6), F (1) and G (2). Regarding sex 15 portfolios were written by women (60\%) and 10 by men (40\%) between seme- 
sters 2009.1 to 2011.2, totaling six periods.

The corpus formed by Alceste ${ }^{\Theta}$ consisted of 14,203 distinct words (mean frequency of nine times) and 2518 Elementary Context Units (UCE), with 77\% utilization of the material, divided into five classes (Figure 1).

\subsection{New Ways of Learning}

In first word class (New Ways of Learning), with the highest percentage (34.03\%), the most frequent and significant words were disciplin+ text+, teamwork, form+ professional+, skill+, practice+ and learn+. Addresses the initial moments of discipline when students are presented to activities that they will play in tutorial groups and when they demonstrate many expectations.

The term "teamwork" refers to a text discussed and experienced during classes, in permanent contact with the complexity of the problems identified in reality. This takes its importance when the students realize that to achieve a common goal (in this case an intervention activity to be held at the end of the semester), they will have to start working together.

So, it is possible to see the discipline walking to orientate to the importance of the relationship between members of a team in health, generating in student the expecting of develop skills to coexist with the peculiarities of others, expressed by different ways of thinking, speaking and acting:

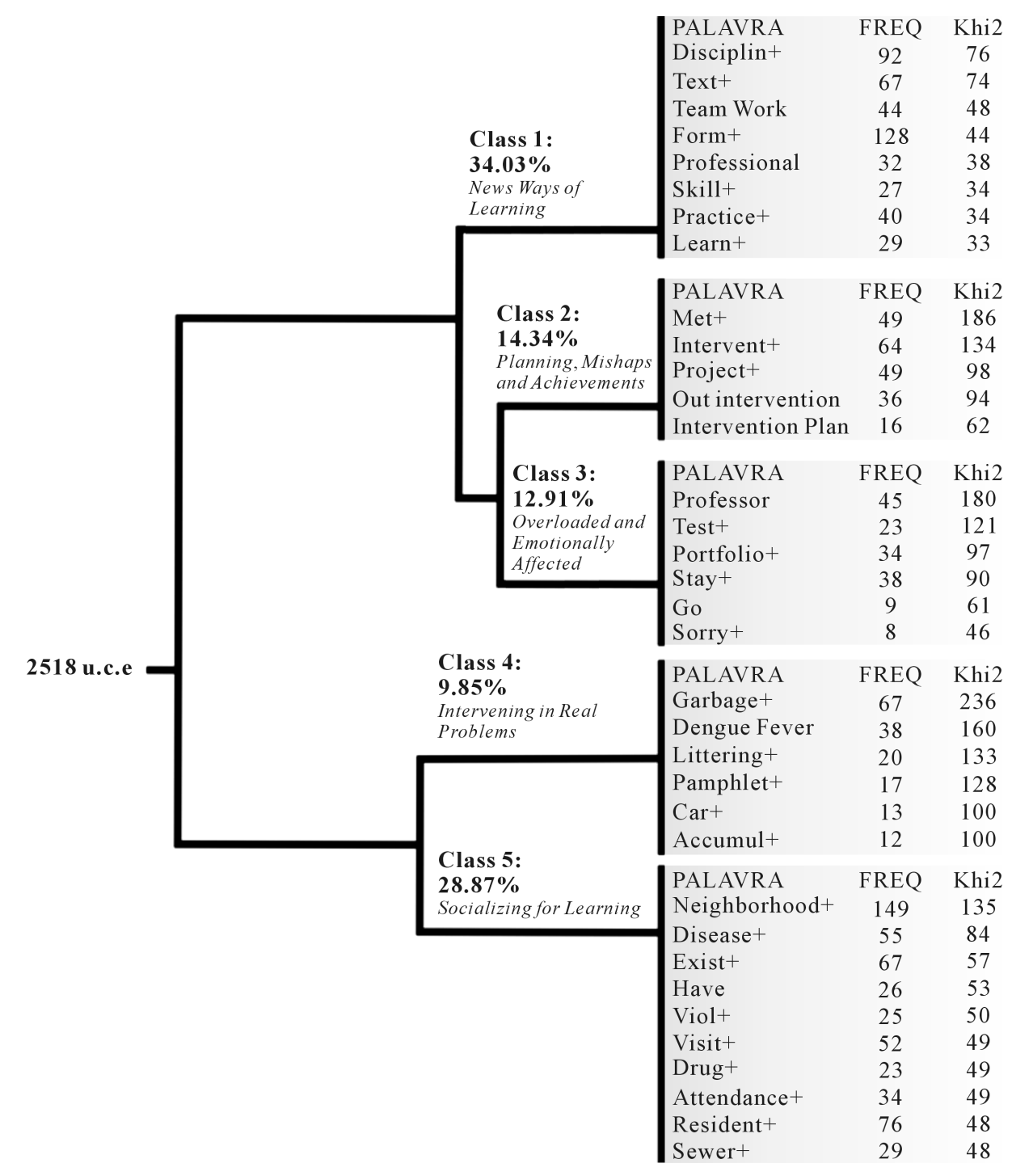

Figure 1. Dendogram corpus Portfolios-SACI, Natal-RN (2012). 
"So I can say that we have the opportunity to expand our knowledge as undergraduates who wish to become health professionals becoming, showing the need for social interaction and for the exercise of citizenship and also I believe that we have personal experiences that will help us in our personal and professional growth”. (subject 7, Medicine, women, HC C, 2010.2, Khi2 = 22)

These moments of preparation for an action are favorable to a horizontal relationship among all members of the tutorial group. At the time of a dynamic, e.g. preceptors and tutors take the same attitude of a student and this favors dialogue.

Within the meaning of Baptist [5], education in a dialogical and critical perspective (where the student ceases to be a passive recipient of content transmitted by the professor and becomes the subject of his/her learning), linked to a socio-historical-cultural concept of health that recognizes the importance of multiprofessional care, is essential to what he calls Inter professional Health Education (IHE).

In IHE the learning is shared between two or more professions and it is characterized markedly by teamwork, the discussion of professional roles, the commitment in solving interdependent problems and negotiating decision making. According to the author, in Brazil the IHE's potential spaces have been revealed in the experiences and stories of experiences in undergraduate by Pro-Saúde and PET-Saúde [5].

So, SACI approaches of this concept and shows a differential when compared to disciplines taught at UFRN in more traditional character. Conversely the latter seeks to prepare students to first understand the social environment that will be the future field of work, rather than nominate a decontextualized technical knowledge and little suited to the demands of today's market expertise, whether in public or private institutions.

\subsection{Planning, Mishaps and Achievements}

The second class (14.34\%) had the words met+ intervent+ project+, our intervention and intervention plan in highlighted. It is evident the moment when students discuss collectively with themselves and with the community to develop a intervention plan that generates benefits, i.e., it is desired, in accordance with the objectives of the discipline, that this plan be able to promote exercise-citizenship in favor of a satisfactory state of health.

"At the end, we feed this hope even more because we were going along with them to develop a schedule for the activities to be performed in the center, if it were reopened which would be delivered." (subject 14, Medicine, men, HC G, 2009.1, Khi2 = 37)

Some problems arising from the choice of the intervention project were perceived in corpus's reading, according to the next UCE. Despite some disagreements, they considered this moments like positive by learning to negotiate between team members and/or by the own action itself.

"Today, we continued our planning intervention project, turning it into something more concrete and tangible. The community leaders were invited to attend our meeting, so they could help us. Just want to say how the dialogue didn’t happen.” (subject 24, Medicine, men, HC B, 2010.1, Khi2 = 24)

The lack of dialogue with tutors, mentors and leaders, expressed in the previous UCE, may reflect paternalistic attitudes that not consider what the community thinks in fact. This tends to the imposition and carrying on to a poor receptivity. It can also enter in the patronizing question of the tutor and the preceptor that try to protect students, but leads to prioritization of issues they believe are most relevant to students by imposing choices against their wills. Although the document does not make clear the reason for the lack of dialogue, the student mentions in the portfolio that it was triggered by imposing attitudes of mentoring and preceptorship.

The problematization pedagogy aims to develop educational activities where the subjects of the process (learner/educator) remain to be consistent and try to overcome the situation of mere repeaters, breeding and uncritical consumers of information passively. The central idea is to form active subjects, coherent, reflective and socially responsible in the construction process of knowledge that is relevant to a life of dignity, solidarity and citizenship.

\subsection{Overloaded and Emotionally Affected}

The three-class (12.91\%) presented as highlighted words: professor, test + portfolio, stay+, go and sorry + . It shows students reporting difficulties in attending training activities and also it revels problems of interpersonal 
relations.

"I wish I had gone because I like to be in the organization of things, but it was difficult. Or I was going to SACI or I was spending the day studying biochemistry.” (subject 23, Nursing, female, HC D, 2010.1, Khi2 = 33)

The problem of students missing classes at SACI recurred in all semesters researched, justified on grounds of illness and also to study for more traditional disciplines of education. It evidences each discipline in a disaggregated, working its contents and it shows the fragility of offering multidisciplinary curriculum components offered occasionally in different health courses at UFRN. Such components rarely communicate, interact, and there is also very few collaborative actions in their planning.

The following UCE comes to interpersonal problems in which the tutor proposed holding an activity day for children in municipal day care. This proposed action had no connection with the final intervention project provided in the syllabus. A student of Medicine disagreed believing that the activity was complex to be performed in a short time and was supported by a fellow student, however, this generated disappointments in the tutorial group:

"To support her, another student, now of Psychology, listed so many difficulties, saying that working with children is very subjective. At that moment, I noticed a certain sadness in the expression of professor . I suppose, like me, she must also think about how simple it is to do an activity like that." (subject 6, Dentistry, women, HC E, 2009.2, Khi2 31/ : tutor)

According to Silva [6] thinking about work in the health permeates interpersonal relationships, since the professional action area involves the communicative process and may result in conflicts that must be reduced in order to achieve the goals set for the solution of problems. Thus, these communicative sounds are not perceived as negative, because they promote individual growth of the students, preparing them for the professional practice of multidisciplinary interaction and, therefore, to act through distinct thoughts. Moreover, from the time the individual is expressed individually, there is a growing autonomy with discerning what is best for themselves and respecting the position of the other. What is needed to reduce conflicts is to teach human understanding, from the exercise of dialogue, mediated and stimulated by tutors.

\subsection{Intervening in Real Problems}

The fourth class has the lowest percentage textual (9.85\%). It was named “Intervening in Real Problems”, revealing the moment when students develop strategies and seek dialogue in the group with the neighborhood residents, to put into practice their plans. It is seen in this class the words garbage+, dengue fever, littering+, pamphlet+, car+, accumul+.

The class was so named because students try to identify problems within the social context in which they operate (HC and territory) to propose solutions. Importantly, this identification of problems through observation of reality does not occur neutrally, in a look merely scientific. According to Maturana and Varela [7], the observation depends on the perceptual experience of the viewer and thus assumes subjective character because it is difficult to discern between "real" environment and perceptions of the beholder. So consider yourself real problems in this class, those identified in the communities from the perceptions of the tutorial group.

If we consider that this class has much smaller percentage when compared to the others, it appears that for students, whose portfolios were analyzed, prepare an action is more significant than develop.

This finding corroborates the study by Silva [8] regarding the valuation of group discussion. Among the teaching-learning methodologies of the discipline Community Health Care I/Faculdade de Medicina de Ribeirão Preto, the 103 students classified in order of importance: 1) Activities in the community, 2) Group discussions, 3) Workshops, 4) Reading and/or individual reflection, 5) Oral and/or written presentation. Protagonist activities should be linked to group interaction and if they were not, they preferred workshops.

In Elementary Context Unit below, the student describes the moment when she was putting into practice the intervention project. In the portfolio she expresses contentment to hear children shouting "Get Out!" interacting and demonstrating that they understood the danger of the proliferation of dengue fever transmitting agent.

"A moment later I went with the mask of Aedes aegypti and I started putting some bottles, caps, plastic tires on the ground, tried to kick me out and I told the kids that if they join trash, water in the covers, in 
the tires and in the bottles I would born.” (subject 5, Nutrition, female, HC A, 2010.2, Khi2 70/ : SACI’s student)

It is noticed that the discipline satisfactorily sharpens on the student the power of argument to convince the community about the importance of the participation of each and every one in the collective action to confront the health problems.

\subsection{Socializing for Learning}

The second largest class (28.87\%), "Socializing for Learning” had as more present words: neighborhood+, disease+, exist+, have, viol+, visit+, drug+, attendance+, resident+, sewer+. It reflects the moments of exploratory walks in territory at Health Center when the group knows the social infrastructures and comes in contact with the population, identifying problems.

For some, these first contacts with suburbs generate unrest and discontent with the things that they see. On the other hand, they see positives amid the problems facing by the community.

All class 5, relates directly to the power that active teaching methodologies have in instigating looking for comprehensive care, since users and, more broadly, community begin to be seen in its complexity, as beings humans, physiologically identical to the others, but particularly distinct with respect to the specific social context in which they operate, as it is showing in excerpt below:

"It was on August 23 that I discovered that acting in a neighborhood is not only to take care of patient's illness, but also to know how that neighborhood survives, as that population is sustained, as the HC helps in healing for their illnesses.” (subject 22, Nutrition, female, HC E, 2010.1, Khi2 23)

The question of completeness, as one of the fundamental principles and guidelines of care practices in health, requires training in the field of health without dissociating the care of the management, the thought of the life, where caregivers also plan the care. For this, there are not ideal pedagogical political models, but the principles and methods of making the training should be built on the inseparability of care, managing and training [9]. Thus, when training in tutorial groups allows social and multidisciplinary interaction, it can be considered a way to form active professionals that know how to recognize the values and contributions of all those involved in the care, including the users of health services.

For this to occur, it is necessary to extend the concept of health, understood not only in the biological aspect, but passing the social impact and the cultures habits, ranging integrating and forming the set of disease prevention and health promotion measures .

\section{Conclusions}

The experiences reported by students of SACI showed the potential of the adoption of the problem-based learning methodology in health education in which students develop skills that they will need for future professional activities. They develop when they are living with tutorial groups and with the community in HC's territory areas and also when they are observing realities through exploratory tours and by realizing the intervention projects.

Nevertheless, we identified weaknesses pertaining to interpersonal relationships causing communication noise, but that are part of the dialogue. They should be mediated by tutors and preceptors so as not to interfere in the SACI's progress. In the curriculum dimension, the lack of discipline in communication with the other curriculum components was perceived as causing harm to students, since they lack the class to study for tests of more traditional subjects when the National Curriculum Guidelines point to the study of content articulately.

It is concluded that the SACI by providing contact with the population of students goes beyond identifying problems and puts an intervention in practice, providing mainly a distinctive way to the future professional practice where the care goes beyond the biological dimension and enters in the understanding of the physical, social, economic and cultural factors that underlie individual and community.

\section{References}

[1] Mendes, E.V. (2012) O cuidado das condições crônicas na atenção primária à saúde: O imperativo da consolidação da estratégia da saúde da família. Organização Pan-Americana da Saúde, Brasília. 
[2] Gil, A.C. (2002) Como elaborar projetos de pesquisa. 4th Edition, Atlas, São Paulo.

[3] Conselho Nacional de Saúde, Ministério da Saúde, Brasil (2012) Resolução 466/2012. Trata de pesquisas e testes em seres humanos e atualiza a resolução 196/96. Diário Oficial da União, Seção 1, 59-62.

[4] Camargo, B.V. (2005) Alceste: Um programa informático de análise quantitativa de dados textuais. In: Moreira, A.S.P., Camargo, B.V., Jesuíno, J.C. and Nóbrega, S.M., Org., Perspectivas teórico-metodológicas em representações sociais, UFPB/Editora Universitária, João Pessoa, 511-539.

[5] Batista, N.A. (2012) Interprofessional Education in Health: Concepts and Practices. Caderno Fnepas, 2, 25-28.

[6] Silva, M.J.P. (2011) Comunicação tem remédio: A comunicação nas relações interpessoais em saúde. 8th Edition, Loyola, São Paulo.

[7] Maturana, H.R. and Varela, F.G. (1995) A árvore do conhecimento: As bases biológicas do entendimento humano. Dos Santos, J.P., Trans., Psy II, Campinas.

[8] Silva, T.J.J.R. (2009) Avaliação discente da disciplina Atenção à Saúde da Comunidade I. Dissertação, Faculdade de Medicina de Ribeirão Preto, Ribeirão Preto. http://dx.doi.org/10.11606/d.17.2009.tde-15012010-102404

[9] Heckert, A.L.C., Neves, C.A.B. (2010) Modos de formar e modos de intervir: Quando a formação se faz potência de produção de coletivo. In: Secretaria de Atenção à Saúde, Ministério da Saúde, Brasil, Política Nacional de Humanização: Formação e intervenção. Ministério da Saúde, Brasíli, 1, 13-28. (Série B. Textos Básicos de Saúde) (Cadernos Humaniza SUS). 